\title{
The influence of carbon fillers on the thermal properties of polyurethane foam
}

\author{
Ewelina Ciecierska $^{1} \cdot$ Magdalena Jurczyk-Kowalska $^{1} \cdot$ Piotr Bazarnik $^{1}$ • \\ Maciej Kowalski $^{2} \cdot$ Sławomir Krauze $^{2} \cdot$ Małgorzata Lewandowska $^{1}$
}

Received: 2 March 2015/Accepted: 20 July 2015/Published online: 1 August 2015

(C) The Author(s) 2015. This article is published with open access at Springerlink.com

\begin{abstract}
The aim of this work was to investigate the influence of different types of carbon filler on the thermal stability and flammability of rigid polyurethane foams. As a filler, multi-walled carbon nanotubes and graphite fakes were used. Scanning electron microscopy was used to observe the structure of foam and dispersion of nanofiller in polymer matrix. Thermal stability of these composites was determined by thermogravimetry analysis. Test was carried out under both nitrogen and air atmosphere. The degradation products were evaluated by thermogravimetry (TG) combined with infrared spectroscopy (TG-IR) measurements. The activation energy was measured by the Flynn-Wall-Ozawa method from the TG curves. Flammability tests like limiting oxygen index and smoke density were also measured. No significant changes in the thermal stability of the composites were observed. The activation energy of sample containing carbon filler increased. Based on TG-IR, one can notice that there were no differences in the emitted volatile products during thermal degradation. Carbon filler enhanced fire retardancy of polyurethane foam; however, graphite gives better results.
\end{abstract}

Keywords Rigid polyurethane foam - Carbon nanotubes . Expandable graphite · Thermal stability · TG/FTIR . Flammability

Ewelina Ciecierska

ewelina.ciecierska@inmat.pw.edu.pl

1 Faculty of Materials Science and Engineering, Warsaw University of Technology, Woloska 141, 02-507 Warsaw, Poland

2 Company S.Z.T.K. TAPS - Maciej Kowalski, Solec3/5, Łodź, Poland

\section{Introduction}

Polyurethanes possess specific chemical structures consisting of stiff and flexible segments, whose fraction strongly influence their properties. Depending on the fraction of each segment, two types of polyurethanes, namely elastomers and plastomers, can be distinguished. As a result, they can exhibit various mechanical and physical properties; therefore, polyurethanes are widely used in industry. Rigid polyurethane foams appear to be very promising materials for the transport industry, where the reduction in elements mass is of prime importance, as the lighter vehicles will use less fuel. However, the major disadvantage of polyurethanes which prevents them being used in the automotive industry is high flammability. When ignited, they emit toxic gases like carbon monoxide, carbon dioxide and hydrogen cyanide. Recently, much emphasis has been placed on the safety regulations applicable to flame-retardant materials in relation to their toxicity and smoke products [1].

To improve the flame resistance of rigid polyurethane foams, various types of fillers have been used, e.g. halogen compounds, alone or in conjunction with antimony trioxide. However, these traditionally used flame retardants significantly increase the mass of elements. To overcome this drawback, a new form of filler, namely nanofiller, has been proposed. Its main advantage is that even small additions can significantly improve specific properties, e.g. mechanical strength, or ensure flame retardancy without increasing the mass of elements [2]. The most commonly used nanofillers are carbon nanotubes (CNTs), which have high thermal stability both in air and in a nitrogen atmosphere; high thermal and electrical conductivity; high mechanical properties such as Young's modulus of c.a. 1.2 $\mathrm{TPa}$ and a tensile strength in the range of 50-200 GPa [3]. 
At the same time, they possess a low density, and according to the literature data, even a small addition of CNTs to a polymer can significantly improve the strength [4]. The addition of only 5 mass $\%$ of CNTs as a filler to polymer matrix brings about $50 \%$ increase in Young's modulus and about $17.5 \%$ increase in the tensile strength [5].

CNTs are also known to improve the thermal stability of nanocomposites, which can be quantified using thermomechanical diagrams. These improvements result from the reduction in the mobility of macromolecules which is correlated with the interfacial interactions $[4,6]$. By increasing the fraction of CNTs in the composite, one can observe the increase in temperature of $5 \%$ mass loss, which gives the information about the beginning of degradation processes and its activation energy [7].

CNTs possess a high free surface area which implies that van der Waals forces play a crucial role. As a consequence, CNTs have a strong tendency to form agglomerates and their uniform distribution in the matrix is one of the major problems when manufacturing nanocomposites with CNTs. A number of mixing methods have been developed in efforts to obtain uniform nanofiller dispersion. Unfortunately, most of these methods cause fragmentation of the nanotubes which has a major impact on the mechanical properties of the composite [3]. Another interesting carbon filler which improves thermal stability and fire retardancy is graphite $[8,9]$. However, its addition can lead to a reduction in mechanical properties of the composites [1]. It was demonstrated that the addition of graphite nanoflakes to thermoplastic polyurethane could improve the thermal stability of the nanocomposites, reduce their heat release rate (HRR) and improve their flame retardance [10].

Although there are a lot of data of the influence of both CNTs and graphite on mechanical and thermal properties of polymer-based composite, only little is known about their impact on the properties of polyurethane foams. Therefore, the aim of the reported work was to investigate the influence of two types of carbon filler, graphite and CNTs, on the thermal stability and flammability on polyurethane foams.

\section{Experimental}

\section{Materials}

Polyurethane liquid system Elastoflex E3509/Iso PMDI 92140 supplied by BASF was used to produce the foams. The fillers used to improve the properties of polyurethane foams were multi-wall carbon nanotubes with an average diameter c.a. $9.5 \mathrm{~nm}$, average length of $1 \mu \mathrm{m}$ and $95 \%$ purity supplied by Nanocyl and Graphite Blahgrafit S-7 supplied by Grafitbergbau Kaisersberg Ges.m.b.H. Four types of composite samples were prepared: containing 3 or 5 mass $\%$ graphite, and 0.05 or 0.1 mass $\%$ of CNT. Pure polyurethane foam was used as a reference sample.

\section{Manufacture}

The dispersion of CNTs in the polymer matrix was obtained using an Exakt 80 three-roll mill. In this mill, each roller goes in different direction to the previous roller. The milling parameters can be varied by changing the distance between the rollers and the rolling speed. Firstly nanotubes were added to polyol and mixed several times starting with a roller gap of $50 \mu \mathrm{m}$. The gap distance was subsequently reduced from 20 to $10 \mu \mathrm{m}$ at the end of processing. Next, isocyanate was added and the components were mixed and placed in a mould. Graphite was added to polyol and isocyanate and was dispersed simply by a mechanical stirrer. Pure PU was obtained by mechanical stirring of two liquid components: polyol and isocyanate. The samples were foamed in the S.Z.T.K. TAPS company, in a metal mould under high pressure.

\section{Characterization}

The morphology of manufactured foams was analysed using scanning electron microscopy. For observations, surface of sample fracture was covered with gold. Highresolution scanning microscopy was also used to control dispersion of nanotubes in polymer matrix. Influence of filler addition on foam structure and foam growth was also investigated.

The thermal stability of the samples was determined by thermogravimetric analysis TGA Q500 TA Instruments in a nitrogen atmosphere and air. The sample mass was about $10 \mathrm{mg}$, the temperature range varied from room temperature up to $800^{\circ} \mathrm{C}$ and the heating rate was $10^{\circ} \mathrm{C}$ per minute. The degradation products formed by each type of carbon filler were evaluated by thermogravimetry combined with an infrared spectroscopy (TG-IR) measurements. In this case, sample mass was about $6 \mathrm{mg}$ and the heating rate was $20{ }^{\circ} \mathrm{C}$ per minute. The TG-IR technique provided information about the volatile products arising during the pyrolysis and the mechanism of thermal degradation. During the TG/FTIR experiments, spectra were repeatedly collected as interferograms and then processed to build up a Gram-Schmidt reconstruction, each point of which corresponded to the total IR absorbance of the evolved components in the spectral range $4000 \div 500 \mathrm{~cm}^{-1}$. Consequently, the Gram-Schmidt plot was formed by averaging the intensities of all FTIR peaks over the entire spectral range $[11,12]$. Thus, the total 
absorbance intensity of each mass loss is a function of the concentration of the evolved gases and their corresponding infrared extinction coefficients [12]. The activation energy was calculated by the Flynn-Wall-Ozawa method from the TG curves at different heating rates of $5,10,15$ and $20{ }^{\circ} \mathrm{C}$ per minute. The flammability of the samples was determined by limiting the oxygen index (LOI) measurements according to the ISO 4589 standard. Testing of the smoke was carried out in a smoke chamber (NBS Smoke Density Chamber) in accordance with UIC 564-2 appendix 13. This test measured the loss of light transmission through a collected volume of smoke produced under controlled conditions. In the sealed chamber, specimens of dimensions of $120 \mathrm{~mm} \times 100 \mathrm{~mm} \times 13 \mathrm{~mm}$ were exposed to a radiant heat source of $25 \mathrm{~kW} \mathrm{~m}^{-2}$ using a pilot flame. The average light intensity $(E)$ after 4 min was determined.

\section{Results and discussion}

SEM images of fracture surfaces of composite samples are presented in Fig. 1. For foams with either nano- or microfillers, changes in the foam structure can be observed. The size and shape of the pores are different to those observed in 'pure' polyurethane foam. In particular, on the bottom of the foams - the arrows indicate the direction of foam rise in the mould-a porosity-free region, can be observed, although the samples were all produced using the same conditions. The presence of these regions is a result of the addition of carbon fillers which slows down the crosslinking reaction in the foams. This phenomenon can be explained by the changes in the viscosity of the matrix caused by the addition of CNTs. It is well known that uniformly dispersed nanotubes have a very high free surface area, and this changes the viscosity of such mixtures [13].

The dispersion of the particles of carbon fillers are presented in Fig. 2. It is clearly visible that CNTs are uniformly distributed in the matrix, without agglomerates, and the individual nanotubes can be easily seen (Fig. 2a). It should also be noted that they are well bonded with the matrix as no cracks or voids are visible. The graphite flakes are also uniformly distributed in the composite structure, as illustrated in Fig. 2b. However, voids are visible at interfaces between the graphite particles and the polyurethane matrix.

\section{Thermal analysis}

The thermogravimetric (TG) and derivative thermogravimetric (DTG) curves for pure polyurethane (PUR) and the composites were obtained at a heating rate of $10{ }^{\circ} \mathrm{C} \mathrm{min}^{-1}$. The results of the analysis are summarized in Table 1 . The onset temperature of degradation $\left(T_{\text {onset }}\right)$ was determined by the intersection of the tangents of the peak with the extrapolated baseline from the first degradation peak of the TG curves [14]. The thermal decomposition of polyurethanes, in both nitrogen and air atmospheres, takes place in two stages. It is well known that the thermal degradation process of polyurethane foam is dependent on the chemical structure of polymer and the pertaining atmosphere during the investigation [15]. The thermal degradation process commences with the decomposition of the weakest bonds. The temperature at which this phenomenon begins depends on the type of the isocyanate (aromatic or aliphatic) and the alcohol from which the urethane groups were built [16]. In literature, this temperature is determined as that at which the samples suffer a mass fraction of 5 or $10 \%[4,17]$. These parameters were determined from the TG curves. $T_{\text {onset }}$ which determines the temperature of decomposition and its character was calculated from DTG curves. $T_{\text {onset }}$ is the most accurate parameter for heterogeneous materials because it characterizes not only mass loss but also dynamics of degradation. $T_{\text {onset }}$ was evaluated for all samples. The initial decomposition of the urethane bonds occurred in the range $292-295{ }^{\circ} \mathrm{C}$ for each material. The highest $T_{\text {onset }}$ in the nitrogen atmosphere was found for polyurethane with an addition of 0.05 mass $\%$ of nanotubes. In air, $T_{\text {onset }}$ was higher with increasing amounts of CNTs. In both atmospheres, $T_{\text {onset }}$ was lower for polyurethanes with additions of graphite (Table 1).
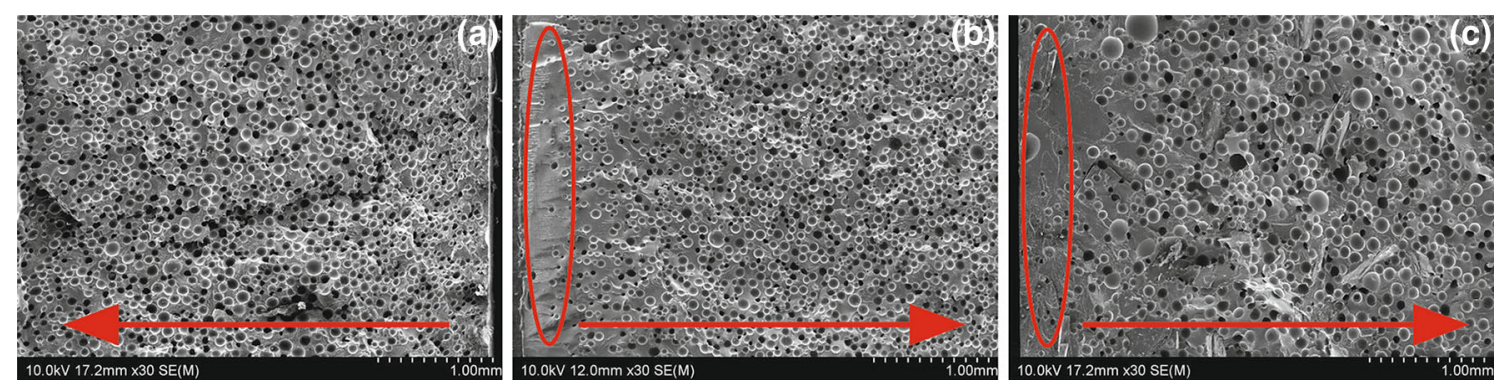

Fig. 1 SEM images of foams: a PUR; b PUR $+0.1 \%$ CNT; c PUR $+5 \%$ graphite 


\section{(a)}
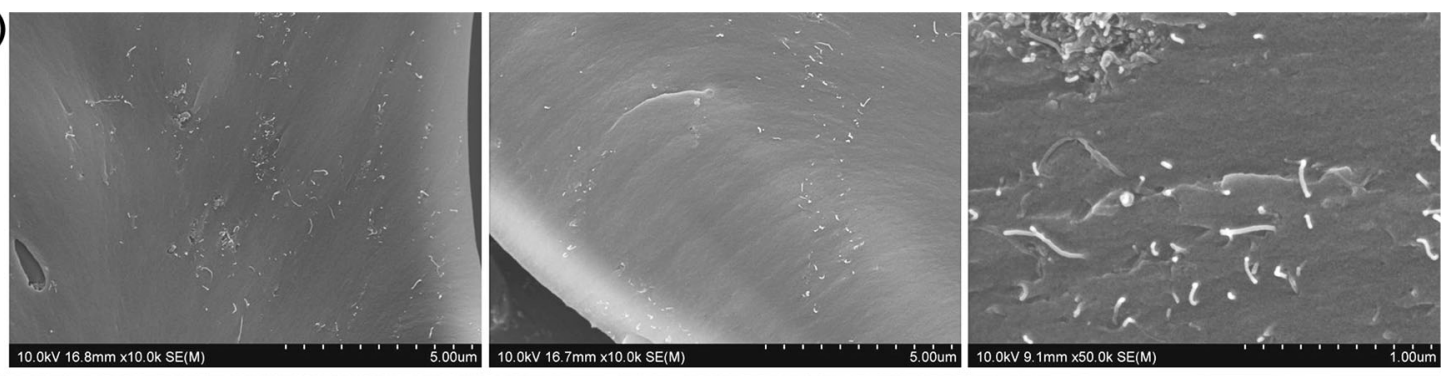

(b)
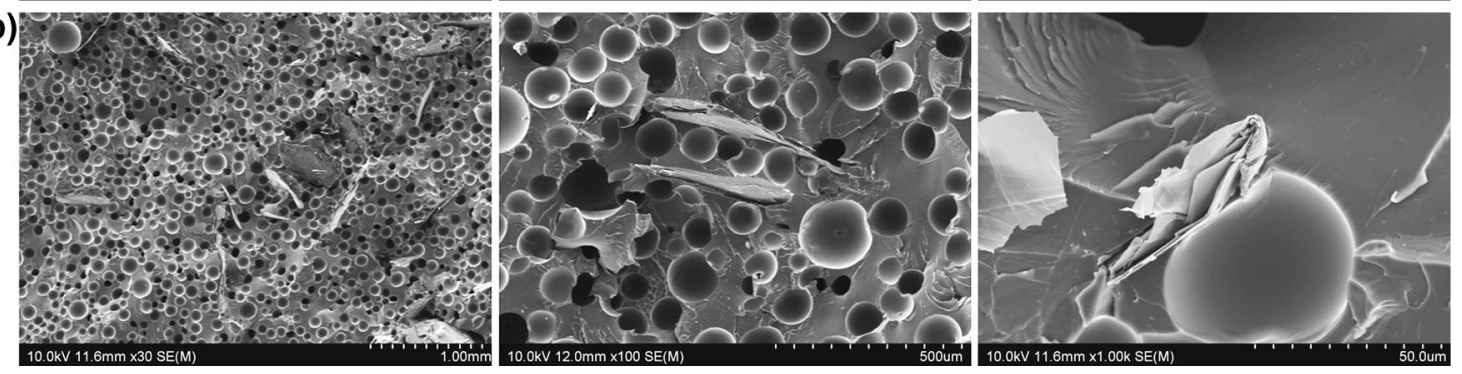

Fig. 2 SEM images of composites a PUR $+0.1 \%$ CNT; b PUR $+5 \%$ graphite

Table 1 The characteristic temperature of degradation $\left(10{ }^{\circ} \mathrm{C} \min ^{-1}\right)$

\begin{tabular}{|c|c|c|c|c|c|c|c|c|c|c|}
\hline \multirow[t]{2}{*}{ Sample } & \multicolumn{5}{|l|}{ Nitrogen } & \multicolumn{4}{|l|}{ Air } & \multirow[t]{2}{*}{$L O I / \%$} \\
\hline & $T_{\text {onset }}^{\mathrm{a}} /{ }^{\circ} \mathrm{C}$ & $T_{\max 1}^{\mathrm{b}} /{ }^{\circ} \mathrm{C}$ & $T_{\max 2}^{\mathrm{c}} /{ }^{\circ} \mathrm{C}$ & $\begin{array}{l}\text { Char residue at } \\
600{ }^{\circ} \mathrm{C} / \mathrm{mass} \%\end{array}$ & $E_{\mathrm{s}, \mathrm{av}}^{\mathrm{d}}$ & $T_{\text {onset }} /{ }^{\circ} \mathrm{C}$ & $T_{\max 1} /{ }^{\circ} \mathrm{C}$ & $T_{\max 2}{ }^{\circ} \mathrm{C}$ & $\begin{array}{l}\text { Char residue at } \\
750{ }^{\circ} \mathrm{C} / \mathrm{mass} \%\end{array}$ & \\
\hline PUR & 293.5 & 331.1 & 405.3 & 17.31 & 170.1 & 287.8 & 331.7 & 562.6 & 0.48 & 24.1 \\
\hline PUR $+0.05 \% \mathrm{CNT}$ & 295.3 & 332.5 & 406.2 & 17.21 & - & 288.4 & 331.3 & 558.5 & 0.64 & 24.9 \\
\hline PUR $+0.1 \%$ CNT & 294.8 & 331.1 & 412.3 & 17.73 & 210.2 & 292.1 & 334.6 & 572.3 & 0.49 & 25 \\
\hline PUR $+3 \%$ Graphite & 294.3 & 327.4 & 402.8 & 18.99 & - & 284.7 & 323.9 & 549.9 & 2.00 & 28.8 \\
\hline PUR $+5 \%$ Graphite & 292.3 & 328.5 & 402.2 & 19.48 & 210.4 & 283.8 & 319.6 & 545.1 & 2.75 & 33.4 \\
\hline
\end{tabular}

${ }^{a}$ The onset temperature of the first-step degradation

b The temperature of the peak maximum at the first step of degradation

c The temperature of the peak maximum at the second step of degradation

d Average activation energy of the $90 \%$ degradation

As mentioned earlier, the thermal degradation process of polyurethane foams proceeds in two stages. The temperature promoting the maximum rate of each degradation stage ( $T_{\max 1}$ and $T_{\max 2}$ ) was also measured in air and in nitrogen. The first stage is related to the degradation of urethane bonds, and in both atmospheres, it was observed at the same temperature. The degradation products formed during the initial stage of degradation have a major influence on the subsequent degradation of polyurethane foams. In a nitrogen atmosphere, the second stage of degradation occurred in the range of $402-412{ }^{\circ} \mathrm{C}$; however, in air it occurred between 545 and $572{ }^{\circ} \mathrm{C}$. In an air atmosphere, different degradation products are formed. For pure polyurethane and its CNT composites, new small peaks appeared in the temperature range between 370 and $500{ }^{\circ} \mathrm{C}$. They can be attributed to the degradation of additional bonds or groups in the material. Depending on the amount of CNTs, the character of these peaks on DTG curves changes. One can conclude that the temperature of second-step degradation $\left(T_{\max 2}\right)$ is determined by the processes occurring in this temperature range. For polyurethane containing 0.1 mass\% of CNTs, the degradation products formed in first decomposition step have a major impact on the thermal stability of the rest of bond in material by increasing their degradation temperature. In the oxidative atmosphere, even a small addition of CNTs (0.1 mass\%) to polyurethane composite leads to an improvement of thermal stability of bonds, whose degradation takes place in the second stage of degradation [17]. For polyurethane with graphite addition, no additional peaks on DTG curves in temperature range $T_{\max 1}$ and $T_{\max 2}$ were observed.

The addition of graphite results in lower temperatures for both stages of degradation and may be explained by the 
expandability of the graphite which takes place in the temperature range of $150-200{ }^{\circ} \mathrm{C}$ [17].

The kinetic parameters of polymer degradation from TG have been characterized by the activation energy calculated from experimental thermogravimetric data. This method requires four TG curves taken at different heating rates: 5 , 10, 15 and $20{ }^{\circ} \mathrm{C} \mathrm{min}^{-1}$ in nitrogen atmosphere. The activation energies of sample conversion are given in Table 1 and in Fig. 3.

It is well known that degradation reaction kinetics is strongly dependent on the additives introduced to the polymer matrix [18-20]. At a particular elevated temperature, intensive breaking of the weakest bonds in the polymer occurs. The stability of these bonds is responsible for the thermal resistance of the particular polymer [4]. Because of the high heat capacity of CNTs or graphite, their introduction to a polymer increases the thermal conductivity leading to an increase in the heat capacity of the composites and changes in the activation energy, $E_{\text {activation, }}$, for the initial stage of degradation [18, 21, 22]. For 'pure' polyurethane, the $E_{\text {activation }}$ measured at $10 \%$ of polymer conversion was about $215 \mathrm{~kJ} \mathrm{~mol}^{-1}$. The addition of CNTs and graphite changed this value to 260 and $265 \mathrm{~kJ} \mathrm{~mol}^{-1}$, respectively. The activation energy of degradation of the composites was higher than for pure polyurethane; however, the character of the curves was unchanged. The increase in $E_{\text {activation }}$ during heating might be related with higher heat absorption process, resulting from the presence of carbon fillers. The addition of carbon fillers also reduces the mobility of macromolecules and increases the energy level needed for their thermal vibration.

The degradation process and the intensity of volatile decomposition products were analysed. The TG, DTG curves and Gram-Schmidt plots in nitrogen are presented in Figs. 4 and 5, respectively. At higher temperatures the decomposition of polyurethane is related to the rupture of

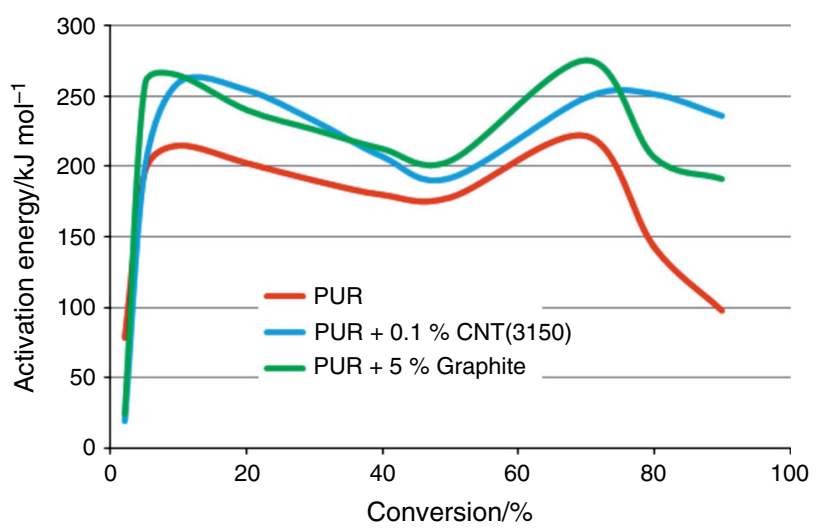

Fig. 3 Activation energy values calculated from the Flynn-WallOzawa analysis of the degradation process of three kinds of foams: a PUR; b PUR + $0.1 \%$ CNT; c PUR + $5 \%$ Graphite weaker urethane bonds [15]. Two characteristic decomposition stages were observed. The first was related to degradation of the hard segments and the second to the soft segments [23]. Both degradation stages of pure polyurethane and its composites were characterized by a high peak as a consequence of the intensive emission of volatile products of decomposition (Fig. 5). Additionally, at temperature between 100 and $230{ }^{\circ} \mathrm{C}$, which corresponds to the time between 5 and 12 min of the test duration, additional peaks were observed on the FTIR spectra and GramSchmidt plot. In this range, the emission of $\mathrm{CO}_{2}$ and $\mathrm{H}_{2} \mathrm{O}$ occurred. Three absorption bands at 668, 2363-2323 and $3735 \mathrm{~cm}^{-1}$, assigned to $\mathrm{CO}_{2}$ and $\mathrm{H}_{2} \mathrm{O}$, were common in all samples [12, 24, 25].

The degradation of polyurethanes commenced at a temperature of $230{ }^{\circ} \mathrm{C}$. The maximum degradation rate for PUR, PUR/CNT and PUR/graphite occurred at the temperature of 351,357 and $348{ }^{\circ} \mathrm{C}$, respectively. Figure 4 shows the two main ranges connected with the emission of volatile degradation products. Additionally, two peaks related to the stages in the degradation process can be observed on the DTG curves shown in Fig. 5.

The FTIR spectra collected for maximum peaks from Gram-Schmidt graph describing individual degradation products are shown in Figs. 6 and 7. The spectra in Fig. 6 were detected at the time of about $17 \mathrm{~min}$ (which corresponds to temperature of $300-350{ }^{\circ} \mathrm{C}$ ), and those in Fig. 7 were detected at the time of about $22 \mathrm{~min}$ (which corresponds to temperature about $430-450{ }^{\circ} \mathrm{C}$ ). The most intense peak on the Gram-Schmidt graph corresponding to the initial stage of degradation was observed at the time of $17 \mathrm{~min}$. The second degradation stage is a much slower process and the intensity of the evolved gases is lower (Fig. 8).

Based on the Gram-Schmidt graph, it is clear that the incorporation of carbon fillers in polyurethane modifies the thermal degradation process and emission of volatile products to longer time. Additionally, expandable graphite brings about a decrease in the intensity of volatile degradation products.

More peaks can be observed on the spectra which are related to the second stage of degradation (Fig. 7). Peaks in the range of $4000-3500 \mathrm{~cm}^{-1}$ are connected to the vibration of $\mathrm{O}-\mathrm{H}$ stretch bond of water or vibration of the $\mathrm{N}-\mathrm{H}$ stretch bond in urethra or urea groups [12, 26, 27]. Peaks at $2964 \mathrm{~cm}^{-1}$ are connected to the $\mathrm{C}-\mathrm{H}$ stretch bond vibration of $\mathrm{CH}_{2}$ and $\mathrm{CH}_{3}$ groups. It was found that the occurrence of small bands at $1647 \mathrm{~cm}^{-1}$ corresponds to $-\mathrm{C}=\mathrm{N}$ bond vibration in carbodiimide [17]. Bands in the range of 1145 and $1052 \mathrm{~cm}^{-1}$ correspond to $-\mathrm{C}-\mathrm{O}-\mathrm{C}-$ and $\mathrm{C}-\mathrm{O}$ stretch bond vibration $[12,28,29]$. Peaks seen above in the range of $2300-2400 \mathrm{~cm}^{-1}$ correspond to $\mathrm{CO} 2$ and $\left(2275 \mathrm{~cm}^{-1}\right)$ to NCO. Peaks at $\left(2960 \mathrm{~cm}^{-1}\right)$ and $(2352$ and 


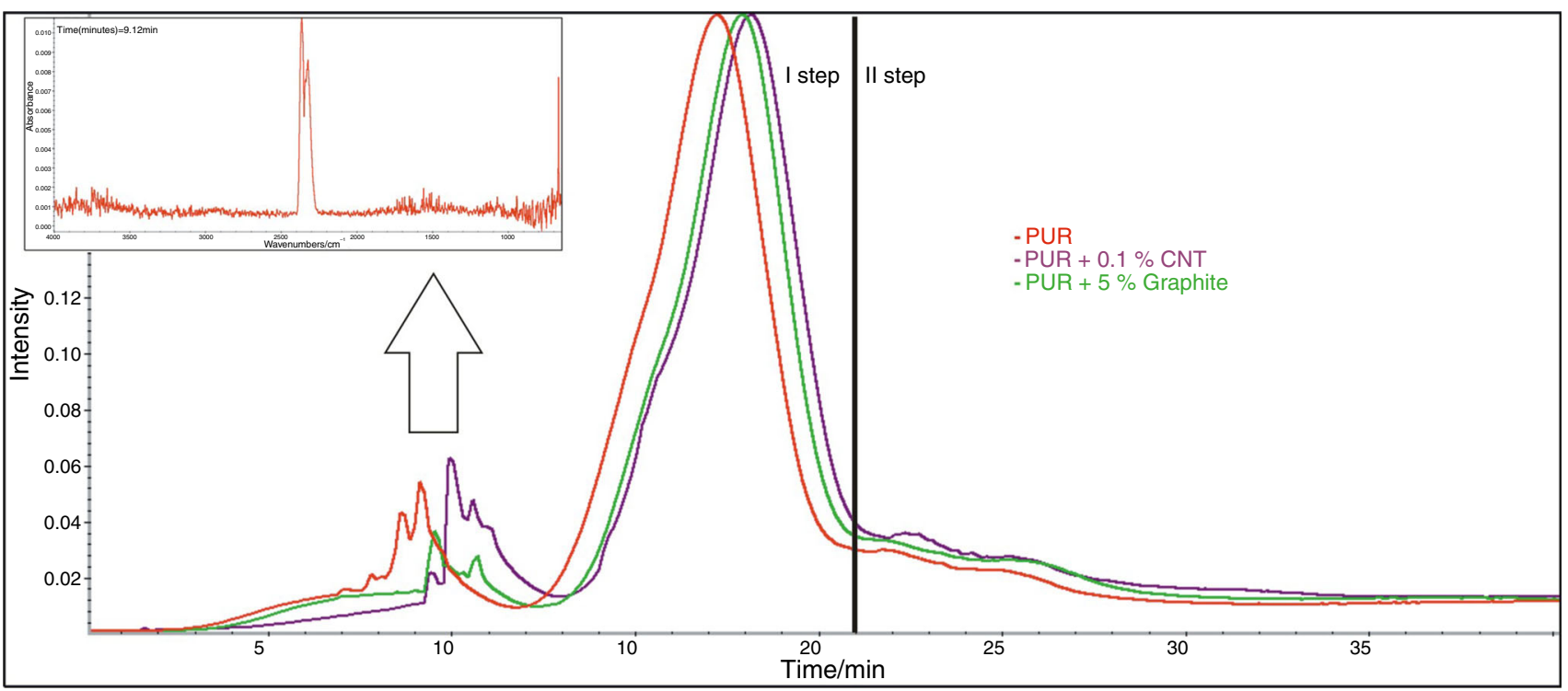

Fig. 4 Gram-Schmidt plots for PU, PU/0,1CNT, PU/5Graphite

Fig. 5 TG and DTG curves for PUR, PUR/0,1CNT, PUR/ 5Graphite samples obtained during TG-IR experiments (nitrogen atmosphere, heating rate $20^{\circ} \mathrm{C} \min ^{-1}$ )

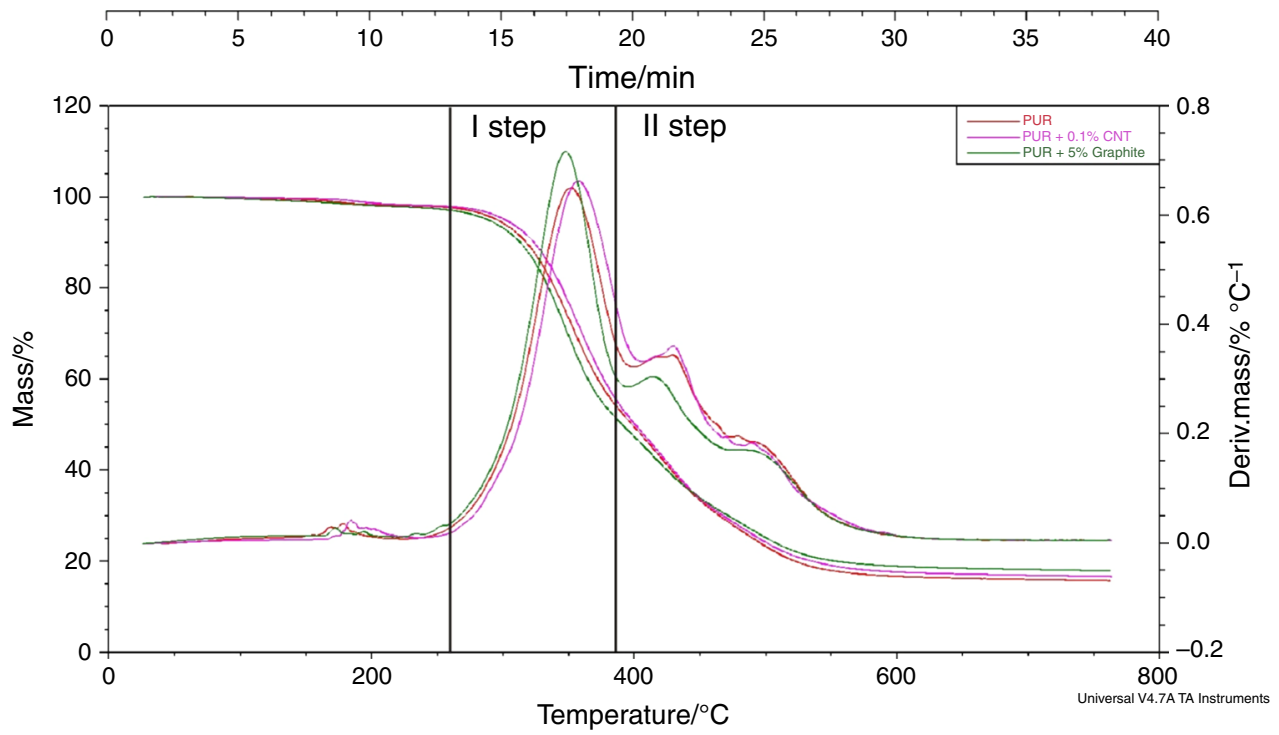

$2310 \mathrm{~cm}^{-1}$ ) correspond, respectively, to $\mathrm{CH}_{3}$ and $\mathrm{CH}_{2}$ groups, and peaks at $\mathrm{CO}_{2}$, aromatic double bond, $\mathrm{NHC}=\mathrm{O}$ and esters correspond to $\left(1596 \mathrm{~cm}^{-1}\right),\left(1528 \mathrm{~cm}^{-1}\right)$ and (1231 and $911 \mathrm{~cm}^{-1}$ ), respectively [29]. The results obtained indicate that the addition of carbon fillers to a polyurethane matrix has no major impact on the emission of degradation products, which can be observed on the FTIR graphs, where no significant changes can be observed and the degradation products appear to be very similar.

\section{Flammability}

The influence of the fraction of carbon fillers on the oxygen index was determined, and the results are presented in
Fig. 9. The addition of CNTs slightly increases the limiting oxygen index (LOI) parameter. However, the highest LOI was observed for composites with graphite, for which the fire resistance raises with increasing amounts of graphite. For a graphite content of 5 mass \%, the LOI value is bigger than $30 \%$, which means that the material is inflammable according to division class given in literature data [30, 31].

The smoke propensity was quantified by measuring the obscuration of a light beam travelling through the smoke generated in the chamber. The addition of CNTs increased average light intensity (E) after 4 min of burning (Fig. 9), which was confirmed by the TG-FTIR curves from which the reduction in the intensity of gas production intensity can be observed. The enhancement of the fire resistance of 


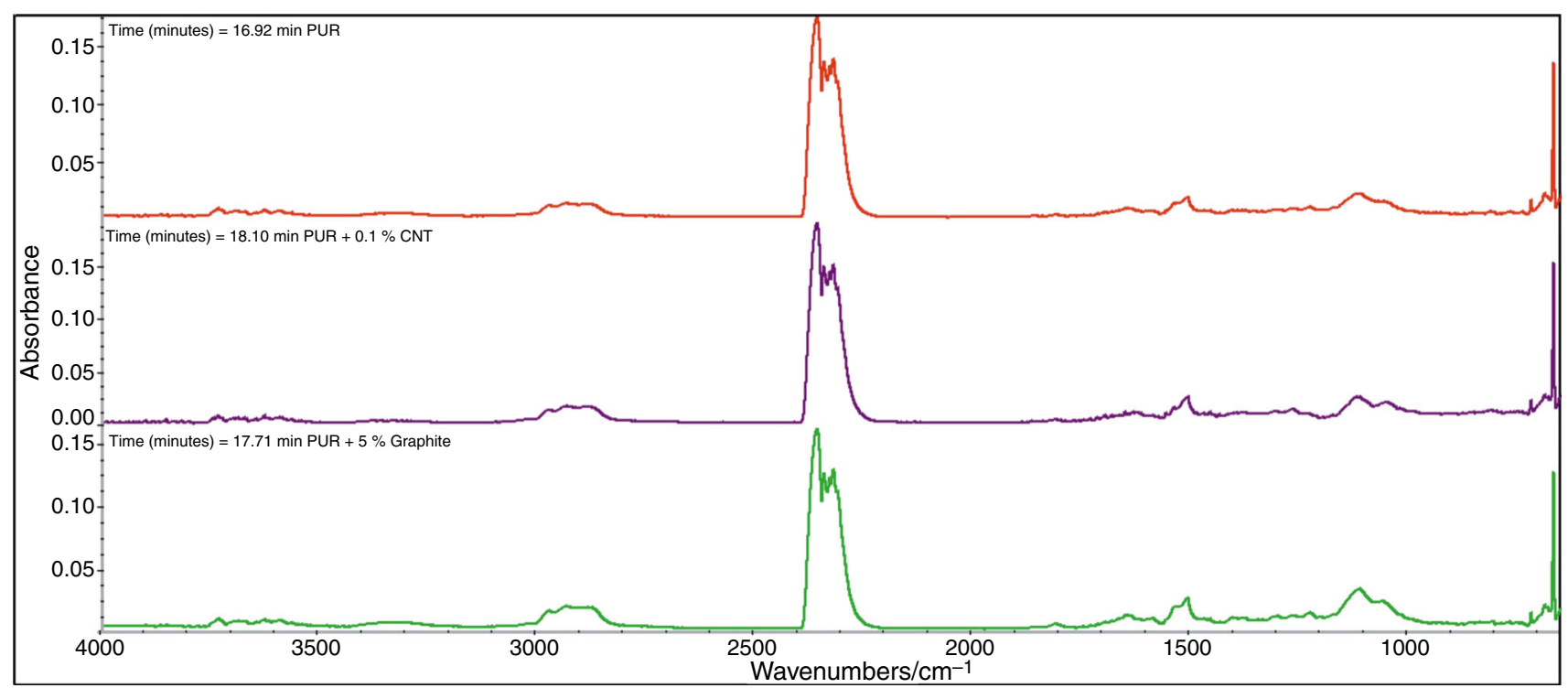

Fig. 6 FTIR spectra obtained for PUR, PUR/0,1CNT, PUR/5Graphite, at the maximum decomposition rate (I step of degradation)

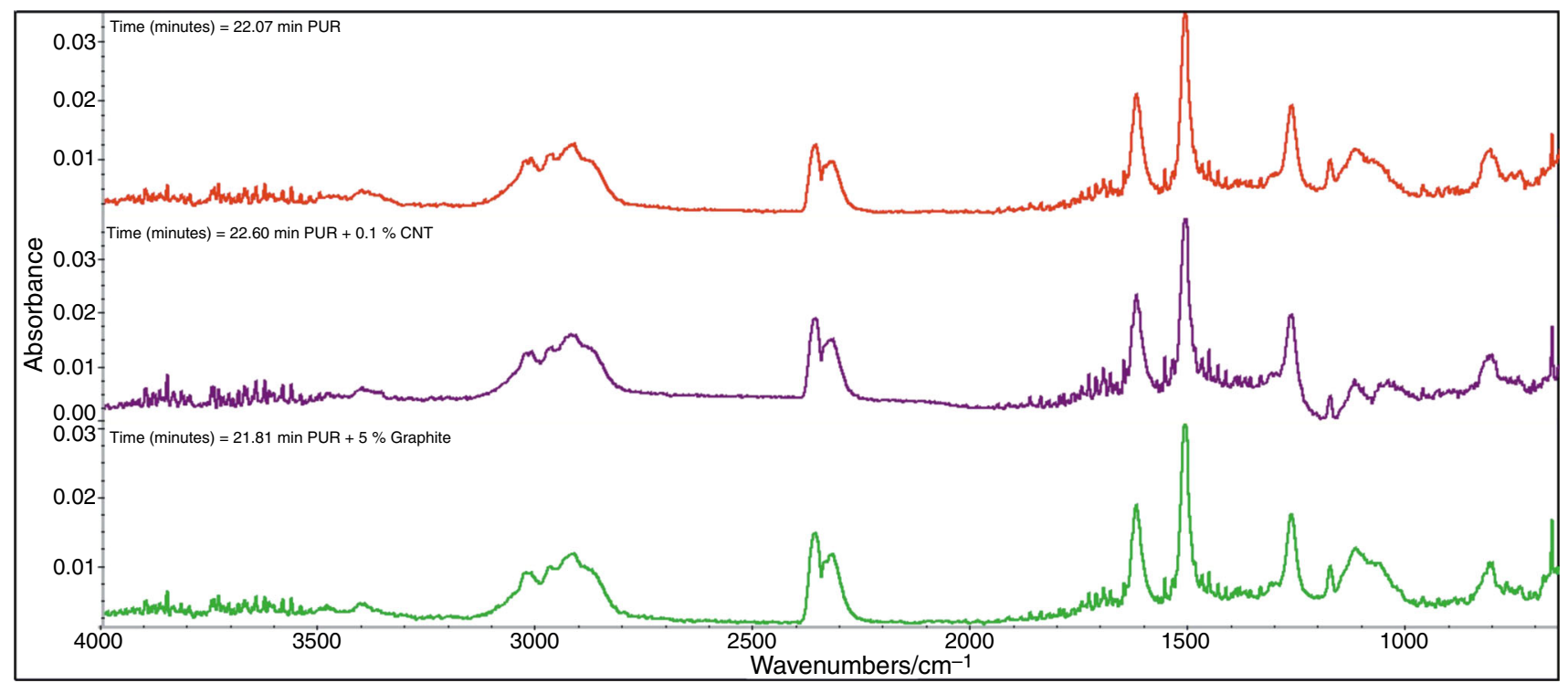

Fig. 7 FTIR spectra obtained for PUR, PUR/0,1CNT, PUR/5Graphite, at the second step of decomposition

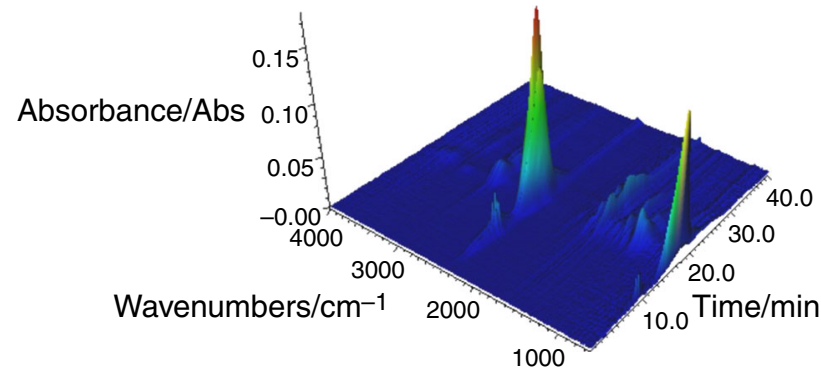

Fig. 8 3D TG-FTIR spectra of polyurethane foam

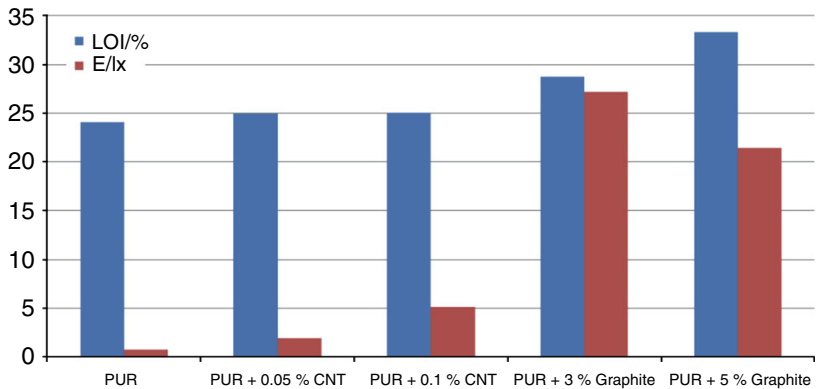

Fig. 9 Flammability of polyurethane foam and its composites 
composites containing nanotubes can be related to the formation of a layer on the surface of the polymer matrix which reduces the flammability [32, 33]. The highest increase in $E$ was observed for the samples with graphite. Manufacture of expandable graphite is carried out by oxidation of graphite flakes in sulphuric acid, which is absorbed into the structure. The mechanism of expandable graphite action is caused by a chemical reaction between the $\mathrm{H}_{2} \mathrm{SO}_{4}$ and the graphite. During degradation, many blowing gases are generated and as an effect the volume of the graphite increases. Exfoliation and expansion along the c-axis of the graphite crystal transforms the lamellar structure of expandable graphite into a vermicular graphite structure [1, 34, 35].

\section{Conclusions}

In this paper, the influence of the type of carbon filler on the thermal properties and flammability of rigid polyurethane foam was evaluated. It was found that both CNTs and graphite have a minor impact on the decomposition process during thermal degradation of polyurethane. The specific conclusions are the following:

1. Although there was no major increase in the thermal stability ( $\left.T_{\text {onset }}\right)$ of the composites, a significant increase in $E_{\mathrm{a}}$ value and the emission of volatile products indicating the initial stage of degradation occurred at a higher temperature. These changes are reflected in the higher LOI for the composites containing carbon fillers. No differences in the emitted volatile products during thermal degradation were detected.

2. The increase in LOI for composites with CNT is probably connected with the formation of a carbon layer on polymer surface.

3. The greatest increase in LOI is connected with the characteristic thermal reactions of graphite. The effect of the transformation of the graphite at temperatures $>150{ }^{\circ} \mathrm{C}$ is a significant change in volume and exfoliation to form a thermal barrier on the surface of the composite which provides enhanced resistance to heat and flame.

4. The use of carbon fillers has a minor impact on the degradation process in air. The degradation process involving the emission of volatile products in air began earliest and at the lowest temperatures for the composites containing graphite.

Acknowledgements This research was financed by the National Centre for Research and Development within the project 'New materials and technologies for lightweight generic components of electric low-emission concept vehicle'.
Open Access This article is distributed under the terms of the Creative Commons Attribution 4.0 International License (http://crea tivecommons.org/licenses/by/4.0/), which permits unrestricted use, distribution, and reproduction in any medium, provided you give appropriate credit to the original author(s) and the source, provide a link to the Creative Commons license, and indicate if changes were made.

\section{References}

1. Ye L, Meng X-Y, Ji X, Li Z-M, Tang J-H. Synthesis and characterization of expandable graphite-poly(methyl methacrylate) composite particles and their application to flame retardation of rigid polyurethane foams. Polym Degrad Stab. 2009;92:971-9.

2. Madaleno L, Pyrz R, Crosky A, Jensen LR, Rauhe JCH.M, DolomanovaV, Madeira Viegas de Barros Timmons AM, Cruz Pinto JJ, Norman J. Processing and characterization of polyurethane nanocomposite foam reinforced with montmorillonitecarbon nanotube hybrids. Composites: Part A 2013;44-7.

3. Ma P-C, Siddiqui NA, Marom G, Kim JK. Dispersion and functionalization of carbon nanotubes for polymer-based nanocomposites: a review. Compos A. 2010;41(10):1345-67. doi:10.1016/j.compositesa.2010.07.003.

4. Morgan AB, Wilkie CA. Flame retardant polymer nanocomposites. Publication: Wiley; 2007.

5. Yeh MK, Hsieh TH, Tai NH. Fabrication and mechanical properties of multi-walled carbon nanotubes/epoxy nanocomposites. Mater Sci Eng A. 2008;483-484:289-92.

6. Park SJ, Seo MK. Roles of interfaces on physicochemical properties of carbon nanotubes/epoxy matrix composites. Adv Res Polym Sci. 2006:133-145.

7. Chou WJ, Wang ChCh, Chen ChY. Thermal behaviours of polyimide with plasma-modified carbon nanotubes. Polym Degrad Stab. 2008;93(3):745-52.

8. Modesti M, Lorenzetti A. Halogen-free flame retardants for polymeric foams. Polym Degrad Stab. 2002;78:167-73.

9. Shi L, Li ZM, Yang W, Yang MB, Zhou QM, Huang R. Properties and microstructure of expandable graphite particles pulverized with an ultra-high-speed mixer. Powder Technol. 2006; 170:178-84.

10. Quan H, Zhang BQ, Zhao Q, Yuen RKK, Li RKY. Facile preparation and thermal degradation studies of graphite nanoplatelets (GNPs) filled thermoplastic polyurethane (TPU) nanocomposites. Compos A. 2009;40:1506-13.

11. Marini A, Berbenni V, Capsoni D, Riccardi R, Zerlia T. Factors affecting the spectra response in a TG/FTIR experiments. Appl Spectrosc. 1994;48:1468-71.

12. Cervantes-Uc JM, Espinosa JIM, Cauich-Rodrigues JV, AvilaOrtega A, Vazquez-Torres H, Marcos-Fernandez A, San Roman J. TGA/FTIR studies of segmented aliphatic polyurethanes and their nanocomposites prepared with commercial montmorillonites. Polym Degrad Stab. 2009;94:1666-77.

13. Wladyka-Przybylak M, Wesolek D, Gieparda W, Boczkowska A, Ciecierska E. The effect of the surface modification of carbon nanotubes on their dispersion in the epoxy matrix. Pol J Chem Technol. 2011;13(2):62-9.

14. Liu Ch, Yu J, Sun X, Zhang J, He J. Thermal degradation studies of cyclic olefin copolymers. Polym Degrad Stab. 2003;81:197-205.

15. Chattopadhyay DK, Webster DC. Thermal stability and flame retardancy of polyurethanes. Prog Polym Sci. 2009;34:1068-133.

16. Król P. Synthesis methods, chemical structures and phase structures of linear polyurethanes. Properties and applications of linear polyurethanes in polyurethane elastomers, copolymers and ionomers. Prog Mater Sci. 2007;52(6):915-1015. 
17. Duquesne S, Le Brans M, Bourbigot S, Delobel R, Camino G, Eling B, Lindsay C, Roels T. Thermal degradation of polyurethane and polyurethane/expandable graphite coatings. Polym Degrad Stab. 2001;74:493-9.

18. Ciecierska E, Boczkowska A, Kurzydłowski KJ, Rosca ID, Hoa SV. The effect of carbon nanotubes on epoxy matrix nanocomposites. J Therm Anal Calorim. 2013;111:1019-24.

19. Zheng X, Wang G, Xu W. Roles of organically-modified montmorillonite and phosphorous flame retardant during the combustion of rigid polyurethane foam. Polym Degrad Stab. 2014;101:32-9.

20. Gao L, Zheng G, Zhou Y, Hu L, Feng G, Xie Y. Synergistic effect of expandable graphite, melamine polyphosphate and layered double hydroxide on improving the fire behavior of rosinbased rigid polyurethane foam. Ind Crops Prod. 2013;50:638-47.

21. Lee GW, Lee JI, Lee SS, Park M, Kim J. Comparisons of thermal properties between inorganic filler and acid-treated multiwall nanotube/polymer composites. J Mater Sci. 2005;40:1259-63.

22. Mortazavi B, Hassouna F, Laachachi A, Rajabpour A, Ahzi S, Chapron D, Toniazzo V, Ruch D. Experimental and multiscale modeling of thermal conductivity and elastic properties of PLA/expanded graphite polymer nanocomposites. Thermochim Acta. 2013;552:106-13.

23. Awad WH, Wilkie ChA. Investigation of the thermal degradation of polyurea: the effect of ammonium polyphosphate and expandable graphite. Polymer. 2010;51:2277-85.

24. Nakamura K, Nishimura Y, Zetterlund P, Hatakeyama T, Hatakeyama H. TG-FTIR studies on biodegradable polyurethanes containing mono- and disaccharide components. Thermochim Acta. 1996;282(283):433-41.

25. Herrera M, Matuschek G, Kettrup A. Thermal degradation of thermoplastic polyurethane elastomers (TPU) based on MDI. Polym Degrad Stab. 2002;78:323-31.
26. Wirpsza Z. Poliuretany, Chemia, Technologia, zastosowanie. Warsaw: WNT; 1991.

27. Wang PS, Chiu WY, Chen LW, Denq BL, Don TM, Chiu YS. Thermal degradation behavior and flammability of polyurethanes blended with poly(bispropoxyphosphazene). Polym Degrad Stab. 1999;66:307-15.

28. Chuang FS. Analysis of thermal degradation of diacetylenecontaining polyurethane copolymers. Polym Degrad Stab. 2007;92:1393-407.

29. Chen X, Huo L, Jiao Ch, Li S. "TG-FTIR characterization of volatile compounds from flame retardant polyurethane foams materials. J Anal Appl Pyrol. 2013;100:186-91.

30. Jurkowski B, Jurkowska B, Rydarowski H. Choosen aspects of flammability tests of polymeric composites. Mech Issue. 2009;3:145-52.

31. Laoutid F, Bonnaud L, Alexandre M, Lopez-Cuesta JM, Dubois $\mathrm{Ph}$. New prospects in flame retardant polymer materials: from fundamentals to nanocomposites. Mater Sci Eng R. 2009;63:100-25.

32. Kashiwagi T, Grulke E, Hilding J, Groth K, Harris R, Butler K, Shields J, Kharchenko S, Douglas J. Thermal and flammability properties of polypropylene/carbon nanotube nanocomposites. Polymer. 2004;45:4227-39.

33. Kashiwagi T, Du F, Winey KI, Groth KM, Shields JR, Bellayer SP, Kim H, Douglas JF. Flammability properties of polymer nanocomposites with single-walled carbon nanotubes: effects of nanotube dispersion and concentration. Polymer. 2005;46:471-81.

34. Modesti M, Lorenzetti A, Simioni F, Camino G. Expandable graphite as an intumescent flame retardant in polyisocyanuratepolyurethane foams. Polym Degrad Stab. 2002;77:195-202.

35. Bhagat VJ. Behaviour of expandable graphite as a flame retardant in flexible polyurethane foam. http://www.metachem.in/Presena tion.pdf. 21.01.2015. 